\title{
Plataforma de hombres cubanos: una experiencia para el bienestar
}

\author{
Plataform of Cuban men. An experience for well-being
}

María Teresa Díaz

\begin{abstract}
Resumen
La Plataforma de Hombres Cubanos por la No Violencia y la Equidad de Género es una agrupación surgida en 2011 e integrada por varones de diferentes áreas de integración social. Sus miembros realizan actividades sistemáticas que redundan en su fortalecimiento, visualidad y desarrollo. A su vez, irradian su influencia en los ámbitos donde desenvuelven sus labores habitualmente: comunitario, religioso, académico, rural, comunicativo-cultural, jurídico, de orden público y de bienestar social, mediante miniproyectos que ejecutan de manera sostenida. Las acciones de la Plataforma contribuyen a contextualizar e ilustrar el valor de la participación de los hombres en procesos transformadores.
\end{abstract}

Palabras clave: género - masculinidades - hombres - equidad - violencia.

\begin{abstract}
The Platform of Cuban Men for the Non-violence and Gender Equity is a group created in 2011 and integrated by men from different areas of social interaction. This program of action performs systematic activities inside the platform that lead to its strengthening, visualisation and development, at the time that radiate and maintain from their fields of action (community, religious, academic, agricultural-rural, communicative-cultural, legal and public order and social welfare) a work of influence in their territorial spaces through mini projects with a serious and sustained work in favour of equity and non-violence.

The actions of the platform contribute to contextualize and illustrate the value of the participation of men in transformative processes.
\end{abstract}

Key words: gender - masculinity - men - equity - violence.

Fecha de recepción: Agosto 2015

Fecha de aprobación: Octubre 2015

Psicóloga, Sexóloga, MSc. Sexualidad, Profesora Auxiliar de la Universidad de La Habana, Coordinadora del Programa de Masculinidades del Grupo OAR. E-mail: maridiaz@informed.sld.cu 


\section{SURGIMIENTO DE UNA NUEVA EXPERIENCIA DE TRABAJO}

El Centro "Óscar Arnulfo Romero" (OAR) es una institución de la sociedad civil que promueve relaciones equitativas de género en la sociedad cubana contemporánea, desde una espiritualidad comprometida con una concepción de derechos humanos y equidad social, y tiene su incidencia en actores sociales diversos en el ámbito comunitario, a lo largo de todo el país. En tal sentido, viene desarrollando procesos de sensibilización, capacitación y acompañamiento a iniciativas locales en los temas de equidad, violencia de género y masculinidades.

En la propia dinámica de las actividades organizadas por OAR, los grupos de varones participantes fueron expresando la necesidad de examinar con detenimiento aspectos presentes en su socialización, que tenían repercusiones importantes en la manera de ser hombres que ellos exhibían.

En el 2011, varones procedentes de diferentes comunidades y espacios institucionales y sociales del país, junto a integrantes de la Red Iberoamericana y Africana de Masculinidades, propusieron crear una estructura que facilitara el trabajo con hombres, desde la experiencia masculina, e incluyera acciones dirigidas al reconocimiento, visualización y cese de la violencia de género. Surge así la Plataforma de Hombres Cubanos por la No Violencia y la Equidad de Género, impulsada por el Centro "Óscar Arnulfo Romero".

La Plataforma está integrada por 52 hombres de diferentes áreas de vinculación social: obreros, campesinos, ingenieros agrónomos, psicólogos, sociólogos, estudiantes universitarios, líderes barriales de las comunidades, líderes religiosos cristianos y de religiones afrocubanas, médicos, profesores de la enseñanza media y superior, juristas, policías, realizadores audiovisuales, periodistas, fotógrafos, diseñadores, actores, deportistas, entre otros. Además de la diversidad de masculinidades atendiendo a profesiones y ocupaciones, la plataforma ha considerado en su integración las diferencias en cuanto a edad, clase social, color de la piel, credo religioso, orientación sexual, entre otras variables de interés.

Los hombres que integran esta agrupación realizan actividades sistemáticas en el seno de la Plataforma y, a su vez, desde sus ámbitos de actuación y vinculación social en cada territorio irradian y mantienen una labor de influencia con un trabajo serio y sostenido a favor de la equidad y de la no violencia de género. En consecuencia, los beneficiarios del proyecto no son solo los integrantes de la agrupación, sino también hombres pertenecientes a las diferentes localidades del país donde viven, laboran e influyen los integrantes de la Plataforma.

Desde sus inicios la Plataforma relevó la necesidad de apoyarse en un cuerpo teórico acerca de lo más significativo para ella en materia de producción científica. Veamos algunos de estos elementos que han constituido su sostén conceptual:

- La violencia de género es el resultado de una estructura patriarcal que potencia la dominación, el control y las relaciones desiguales de poder.

Las asignaciones tradicionales prescritas según las diferencias sexuales de hombres y mujeres tiene un sustento patriarcal, hegemónico, androcéntrico, heterosexista y machista, que se manifiesta en relaciones de dominación-subordinación, en las que las mujeres se encuentran en desventaja respecto de los hombres, a quienes esas relaciones les han facilitado el derecho a ser protagonistas independientemente de cómo se ejerza ese derecho (Bonino, 1995: 4). 
Es importante reconocer que en la construcción cultural de las masculinidades sobre esas bases patriarcales se aprecia cómo se ha desencadenado un mecanismo de poder que permite al varón exhibir múltiples maniobras de control y dominio sobre la vida de las mujeres y de otros hombres, en aras de lograr obediencia y subordinación, pero también competitividad, protagonismo y triunfo.

En general, en las relaciones de poder se crea un contexto de exclusión social, donde se reproducen relaciones de subordinación verticales, y en algunas ocasiones violentas, de ahí la importancia, según Casez (2005), de realizar análisis de género, lo que favorece la comprensión de los mecanismos del orden patriarcal y sus aspectos nocivos, a partir de una organización social estructurada desde la inequidad, la injusticia y las jerarquizaciones de un binarismo que desde las diferencias sexuales se transformó en desigualdad genérica.

- Antiguas brechas de equidad (de clase, de género, color de la piel, territoriales) que se reproducen y acentúan y aparecen como nuevos obstáculos a las relaciones equitativas.

En este mosaico de inequidades en la Cuba de hoy, las de género adquieren una singular relevancia por el grado de desventaja social y personal que representa para las mujeres, a saber: menos representadas en cargos de dirección, brechas salariales con relación a los hombres, invisibilización de sus aportes económicos en el espacio doméstico y en la agricultura, mayor carga en las labores domésticas, situaciones de exclusividad en el rol de cuidadoras (hijos/as, enfermos/as, ancianos/as,) problemas de salud asociadas a la no prioridad de su autocuidado, estereotipos en las identidades de género, por solo situar algunas de las más conocidas (Espina s/a).

La promoción de relaciones humanas basadas en la equidad y la igualdad significa aproximarnos a la justicia social y al ejercicio pleno de los derechos humanos.

- La violencia como la más grave de las desigualdades de género.

Es indiscutible que la violencia de género constituye una de las principales urgencias contemporáneas de nuestro mundo en tanto deviene un problema social, de salud y de derechos. Ella favorece las inequidades y afecta la naturaleza de las relaciones intra e intergenéricas en diferentes espacios de la vida pública y privada, impide el respeto a la dignidad y el reconocimiento al ejercicio pleno de los derechos, lacera la integridad moral de las personas al negarle la posibilidad de hacer elecciones, reclamar o denunciar determinada situación o suceso y tiene impactos de consideración en el bienestar, la calidad de vida y el desarrollo personal y social de los seres humanos. En consecuencia, asumir su inaceptabilidad y eliminación es un principio que garantiza la seguridad de los seres humanos.

Por otra parte la práctica investigativa cubana y el trabajo con hombres ha exhibido resultados interesantes relacionados con las diferentes expresiones de la violencia en el país que también han constituido insumos para la labor de la Plataforma.

Hace años Michael Kaufman (1985), al definir la tríada de la violencia en los hombres, fundamentó cómo cada acto de violencia en los hombres, principalmente los desencadenados hacia las mujeres, no ocurría de manera aislada, sino que estaba estrechamente vinculado a la violencia de los hombres contra otros hombres y a la interiorización de la violencia, es decir, la violencia de los varones hacia sí mismos. 
Un estudio presentado durante 2010 demuestra cómo en Cuba también son las relaciones asimétricas de dominio masculino las que están legitimando la violencia hacia la mujer. La investigación alerta acerca de la necesidad de visualizar esta realidad entre las mujeres y los hombres en tanto para ambos constituye un fenómeno naturalizado. Las primeras, porque no concientizan sus consecuencias nocivas ni la necesidad de protegerse; y los segundos, porque no identifican su conducta como violenta, aun cuando en algunos casos declaran que su forma de actuar no es la mejor manera de resolver los conflictos (Proveyer, Fleitas, González, Munster y César, 2010). ${ }^{2}$

Sin dudas la violencia contra la mujer ha recibido gran atención, no solo por su naturaleza discriminatoria, sino porque es una de las más frecuentes y extendidas, tanto en el ámbito público como en el privado. Tampoco son casuales los reiterados intentos de visibilizar, desnaturalizar, prevenir y atender estas agresiones como parte de políticas públicas, programas sociales y campañas internacionales.

Por otra parte la violencia de varón a varón, legitimada como variante del comportamiento masculino, es una forma de agresión histórica que en las sociedades patriarcales ha sido utilizada como una vía para resolver diferencias y conflictos entre varones, grupos de hombres o naciones (Kaufman, 1998). ${ }^{3}$ Sin embargo, no son los puños o el uso de armas blancas o de fuego los únicos medios para que los varones demuestren su poderío y superioridad ante otros hombres; la burla, las amenazas, los chantajes, la ridiculización, la descalificación y los apodos peyorativos se convierten en credenciales para hacer saber a otras personas su grandeza como hombres.

Las agresiones que asumen los varones hacia otros hombres son también una manera de desarrollar la competencia. Esa forma de violencia de género (como otras) descansa en una relación de superioridad-inferioridad y, en consecuencia, va dirigida siempre a los hombres más débiles (tanto desde el punto de vista físico, como psicológico), los más vulnerables y los que quedan por debajo en la escalera de poder socialmente establecida (Díaz, 2010-2012).

Los resultados de un proyecto de intervención en seis regiones cubanas señalaron a los jóvenes, los hombres más viejos, los migrantes, los negros, los mestizos, los homosexuales y los bisexuales, entre otros, como los más desfavorecidos (Díaz, 2010-2012). ${ }^{4}$ En el estudio se pusieron de manifiesto diversas razones que fundamentan el ejercicio del poder en los grupos analizados.

En los hombres más jóvenes, la falta de conocimientos y experiencia emergió como causa que los coloca en desventaja respecto de los que los superan en años; mientras que los

2 En mayo de 2010 la Agencia de Cooperación Oxfam Internacional publicó un estudio realizado por las investigadoras cubanas "50 años después: Mujeres y cambio social" donde en su capítulo 7, "La violencia de género y sus manifestaciones en Cuba", aparece una detallada referencia al tema.

3 Se trata del trabajo "Las 7 P de la violencia" surgido de un taller realizado por el autor en Katmandú en 1998 organizado por Save the Children / Reino Unido y acompañado por Development Servicies International de Canadá. La discusión del taller se encuentra en el libro de Ruth Finney Hayward, Breaking the Earthenware Jar publicado en el 2000. El canadiense Michael Kaufman, es escritor y experto en temas de género desde hace más de cinco lustros. Se le conoce por ser el impulsor de la campaña del Lazo Blanco contra la violencia masculina.

$4 \quad$ La investigación fue realizada en la capital y algunas provincias del país como sistematización del Proyecto "Bienestar para Masculinidades en Desarrollo" coordinado por el Centro OAR y señaló además los principales escenarios donde estas manifestaciones de violencia ocurren con mayor frecuencia. 
adultos mayores fueron identificados como víctimas de manifestaciones verbales agresivas o de silencios prolongados por haber caducado sus presupuestos "a la hora de mirar la vida".

A los migrantes se les identificó como desprotegidos legalmente, pero además, el desarraigo del lugar de origen debilita los presupuestos de hombría que han construido, al tener que asumir otras maneras de comportarse y ser hombres reclamadas por el nuevo espacio.

El color de la piel fue otra de las condiciones identificadas como generadora de situaciones de violencia mediante exclusiones, discriminación y menosprecio, pero además, los negros y mulatos no se corresponden con el estereotipo de belleza, desde la normatividad masculina.

Los varones cuya elección sexual contraviene la norma heterosexual socialmente pautada y que exhiben "supuestas debilidades", "inseguridades" y "cierta falta de carácter", fueron los más desvalorizados, atacados y marginados dentro del universo masculino. Las conductas de evitación y violencia hacia ellos son incorporadas por los varones heterosexuales como auténtica representación del modelo dominante tradicional de "hombre" (Díaz, 1999).

Otros estudios realizados en Cuba dan cuenta de cómo los hombres cuyo comportamiento se aleja del modelo heterosexual se sienten cuestionados, sancionados y objetos de burlas. Aun cuando en los últimos tiempos la posición del hombre heterosexual cubano contemporáneo hacia ellos ha exhibido miradas más respetuosas y de cierto entendimiento, sigue suponiendo una abierta actitud de repulsa que no admite elección en el campo de la amistad (Díaz, 2009; Ramos, 2003; Pereira, 2003; y Gómez, 2011).

Los trabajos con grupos de hombres han revelado que los actos de violencia entre ellos constituye una forma más de ostentar privilegios. Según el doctor Julio César González (2009, 2011), los deportes se consideran un escenario propicio para expresar el poder y legitimar la posición de hombre hegemónico dentro del grupo. En este ámbito se presentan características y comportamientos propios del modelo de masculinidad tradicional que desde la ideología y la cultura han sido impuestos por quienes sustentan el poderío social.

También los medios de comunicación hacen su parte. El tratamiento a personajes varones en el cine y la televisión, las obras de arte, las imágenes de la gráfica, la letra de canciones y los estilos danzarios, supone un culto al desarrollado al cuerpo masculino (González, 2007) y a sus comportamientos de fuerza, hegemonía y poderío, mientras que los que no cumplen estos requisitos son invisibilizados, ridiculizados y condenados a la burla. A los primeros se les presenta alzando su superioridad como trofeos y a los segundos, sufriendo dolores, temores y tragedias, convertidos en figuras pasivas y acríticas víctimas de diversas agresiones.

Por otra parte las agresiones de los varones hacia sí mismos marcan la lucha individual masculina por cumplir con los paradigmas de lo que es: ser un hombre y aparecen referidas con mucha frecuencia en diferentes escenarios cubanos. Esta situación impide en ocasiones su desenvolvimiento saludable en diferentes esferas de la vida con las consecuentes afectaciones físicas, psicológicas y espirituales.

El propio hecho de situar al varón como eje del universo y resaltar constantemente su fortaleza física y psicológica no favorece en ellos una ética del cuidado y el autocuidado de su salud, por tanto no hay lugar para el llanto, el dolor, la queja y la búsqueda de ayuda. Esto 
hace que se desarrolle una cultura de la "resistencia", del "aguante", del "sobreponerse", del "silenciar" todo aquello que puede conspirar contra esa hombría (Díaz, 2012).

La meta de tener que poder con todo, la responsabilidad de proveer, la competitividad, el habérsele expropiado la posibilidad de mostrarse temeroso, inseguro, desconocedor, vulnerable y tener que exhibir en el espacio público valentía e intrepidez, genera, según la doctora Artiles (2007), estereotipos que funcionan como dispositivos para reconocerse portador de una dolencia o un malestar y mucho menos para demandar atender su salud, lo cual se expresa en resistencias marcadas a involucrarse en acciones de salud. En consecuencia, no dan importancia o callan los malestares, no se chequean ni acuden a las consultas médicas o al especialista ante una señal de alarma, pues todo ello supone, de alguna manera, asumir que se es "débill" o "flojo".

Son variados los ejemplos que servirían para ilustrar los costos de esta masculinidad hegemónica para el bienestar saludable, porque los riesgos que asumen los hombres en materia de salud parecerían riesgos necesarios para probar su hombría: lanzarse en aguas profundas, saltar desde grandes alturas, manejar bicicletas con sobrecarga y loma abajo, cargar pesos excesivos, entre otros. De manera que el desempeño del rol deviene una barrera de contención ante dolencias, malestares y enfermedades que evitan admitirlas o expresarlas.

Los índices de mortalidad de los varones en Cuba son superiores a los de las mujeres y recaen básicamente en elevados niveles de accidentabilidad (asociados a características genéricas como el arrojo, la valentía, la poca precaución); la drogadicción (prácticas asociadas a la resistencia y la virilidad); el suicidio ante la imposibilidad de la queja que los obliga a silenciar sus malestares y buscar formas de evasión; así como las que se asocian a estilos de vida poco saludables (infartos de miocardio, aumento de la tensión arterial, cáncer de pulmón, cáncer de próstata, cirrosis hepática), que en la base, sin lugar a dudas, tienen implicaciones en la forma en que los hombres viven y han sido educados. La doctora Arés (1996) ha denominado patología de la omnipotencia a aquellas dolencias o malestares de los hombres que se derivan del cumplimiento indiscutible de la normativa signada por la cultura para ellos.

El sistema cubano de salud cuenta con numerosos programas que reconocen y previenen patologías privativas de la población masculina, tal es el caso del Programa de detección precoz del cáncer de próstata, que focaliza a los hombres con más de cuarenta años para que acudan a las consultas de prevención. Sin embargo, por lo general tienen una escasa cultura de atención preventiva y se resisten a someterse a chequeos médicos como el examen de próstata, por el mito de considerar que un tacto rectal paraliza su actuación y hace "tambalear"su masculinidad. Similar situación ocurre con examen de las mamas, porque se vivencia como una dolencia típica de mujeres.

Desde el punto de vista de la sexualidad, una de las columnas sostenedoras de la masculinidad hegemónica y de la salud sexual, la aparición de disfunciones sexuales (dificultades en la erección, trastornos eyaculatorios y del deseo), muchas veces son enmascaradas, ocultadas y afectan emocionalmente a los hombres. Por lo general, son experiencias que se prefieren llevar en silencio y frente a los cuales la vergüenza pesa más que la necesidad de buscar apoyo profesional.

También cuentan las agresiones al cuerpo, vinculadas a una cultura de la estética según los cánones de belleza tradicional masculina y que impactan en la figura corporal hegemónica. Si bien el fisicoculturismo es una práctica reconocida, cuando se utilizan procederes vinculados al uso de anabólicos que pueden lacerar la salud, se convierte en un tema de especial atención. Al 
respecto, Juan Guillermo Figueroa (2001) hace un análisis de diferentes posiciones sostenidas por estudiosos del tema, donde además de defender que los derechos deben constituirse y definirse tanto para hombres como para mujeres, señala la necesidad de continuar mostrando a los varones el camino para cuestionar los modelos de masculinidad tradicional, las prácticas de riesgo que tienden a asociarse a estereotipos muy invasivos y la exhortación a relacionarse de otra manera con su espacio corporal en aras de evitar consecuencias negativas para su salud.

\section{UNA PLATAFORMA PARA EL BIENESTAR}

Los avances en la conceptualización teórica de las masculinidades, la violencia y la equidad de género, el desarrollo de estudios acerca del tema y las experiencias prácticas en el trabajo con hombres, favorecen la necesidad de continuar instrumentando enfoques participativos e integradores que permitan poner la mirada en ellos como centro de políticas. En tal sentido esta experiencia de la Plataforma de Hombres Cubanos se propone dignificar al ser humano, para avanzar hacia formas más enriquecedoras de vida. Para ello dirige sus líneas de acción a:

- Fortalecer la integración de la estructura creada.

- Intensificar la capacidad de influencia de sus integrantes en diferentes localidades del país, dotándolos de herramientas conceptuales y metodológicas sobre los temas género, masculinidades, violencia y equidad de género para que ganen en comprensión acerca de la dimensión de estas variables y su valor para lograr transformar la vida de otros hombres.

- Promover espacios territoriales que permitan a hombres de las diferentes localidades ser alcanzados por esta influencia.

- Lograr sinergia entre los integrantes de la Plataforma y distintos miniproyectos locales.

La Plataforma tiene como principio básico respetar los valores y presupuestos que se desprenden de un adecuado enfoque de género, salud, derechos y diversidad. Está concebida para ser instrumentada bajo los presupuestos y potencialidades de la metodología de educación popular, como práctica social transformadora y como conjunto de prácticas educativas que suponen, por una parte, el reconocimiento de la experiencia de vida que tengan estos hombres y, por otra, el principio de construir el conocimiento compartiendo con otras personas en la interacción grupal y masiva. Según la doctora Argelia Fernández (1994), esta edificación de saberes implica su síntesis y elaboración para ser devueltas al colectivo mucho más enriquecidas en el espacio de una relación de horizontalidad.

Sin embargo, trabajar con varones no constituyó un desempeño fácil. Los hombres cubanos no tenían cultura de trabajo grupal y ofrecían resistencias para socializar experiencias y emociones, básicamente durante los primeros encuentros. El arraigo a los mandatos tradicionales de la masculinidad, la solidez en la estructura de emociones mudas, invisibles y aparentemente ausentes, y la consistencia de estereotipos y prejuicios con una marcada permanencia en sus vidas, son algunos de los sustentos que dificultaron en un inicio el intercambio con sus realidades.

En consecuencia, hemos favorecido para el trabajo dentro de la Plataforma algunos procederes metodológicos: 
- Intencionar el trabajo y la cohesión grupal favoreciendo el acercamiento físico y emocional entre los varones, de forma tal que puedan reconocer sus realidades entre y desde los propios hombres, aprender a valorizar la diversidad que representan sus vidas, revisar sus historias, asimilar nuevos retos y mirar hacia puntos más distantes.

- Trabajar desde la demostración de la necesidad de la revisión y no desde la imposición al cambio. No se trata de convocar al cambio desde el reclamo de la mujer o de otros hombres ni desde las exigencias de nuestra época, sino a partir de las reflexiones grupales, la revisión de sus historias de vida, el análisis de la propia visión de culturalización de género para de esta manera demostrar la inviabilidad de determinadas formas de pensar, sentir y actuar, y que esta reflexión pueda devenir en un resorte de convencimiento para la transformación. Asumimos la transformación personal como proceso gradual que supone por una parte la de toma de conciencia y por la otra la voluntad del cambio.

- Demostrar las ventajas de las reflexiones grupales por sobre lo que sería un examen de conciencia individual. Sin dudas, los seres humanos no pueden desprenderse en poco tiempo de sus realidades de vida, pero estos hombres han podido vivenciar que a veces el reto de la automirada es difícil asumirlo de manera independiente y el hecho de lograr una sistematicidad en los contactos, de unirse para pensar y de atreverse a avanzar juntos hacia propuestas hasta ahora desconocidas, en el ámbito de una experiencia grupal, puede resultar de mucho beneficio para todos. Los aprendizajes grupales son decisivos para el crecimiento humano.

- Seleccionar las temáticas que van a intencionar el trabajo grupal y su adecuada colocación en la realidad de nuestro momento. Es preciso incorporar hechos, situaciones, eventos que tengan una conexión con la vida de los hombres.

En el empeño de la Plataforma están comprometidas ocho provincias del país y doce territorios municipales que funcionan mediante siete ámbitos de actuación: comunitario, religioso, académico, agropecuario-rural, comunicativo-cultural, jurídico y de orden público y de prevención y bienestar social. Están conformados siguiendo un criterio de homogeneidad en las profesiones, esferas de trabajos y sitios donde actúan, lo que permite un contacto más objetivo con el personal receptor de las acciones, siempre intencionado sobre la base de una actuación interrelacionada.

Las acciones de la Plataforma están agrupadas en dos bloques: uno referido a las actividades que tienen lugar dentro de la Plataforma y que redundan en su fortalecimiento, visualidad y desarrollo, y otro relacionado con proyectos en las diferentes localidades y espacios de actuación ejecutados, apoyados y monitoreados por integrantes de la Plataforma.

Dentro de la Plataforma se producen experiencias de capacitación por medio de talleres, cursos, conferencias, videodebates; el desarrollo de procesos de investigación, construcción teórica e intercambio científico; sistematización de resultados con buenas prácticas en el trabajo con hombres; la creación de un sistema visual que identifique la Plataforma y todo el sistema de soportes comunicacionales que ella genere; y la presencia de un folleto o manual que guíe y ordene la vida de la Plataforma (funciones, obligaciones de sus integrantes, relaciones, toma de decisiones, términos de referencia, conceptualizaciones e integrantes del grupo gestor). 
Otras actividades integran el cuadro de acciones de los hombres cubanos agrupados en esta agenda de trabajo, tal es el caso de los mensajes de bien público elaborados por los integrantes como apoyatura mediática para ser colocados en diferentes espacios televisivos, radiales y periodísticos; soportes comunicacionales de la gráfica; obras audiovisuales y espectáculos humoristas libres de sexismo y discriminación, entre otros. También aparecen acciones con grupos expuestos a niveles de exclusión social por su condición legal y delictiva (reclusos, hombres prostitutos).

Pero si bien esas maneras de accionar de la Plataforma resultan decisivas, el desarrollo de miniproyectos locales en los espacios de actuación deviene en un resultado sumamente novedoso y participativo. Tal es el caso de talleres de creación literaria, experiencias relativas a rescate de tradiciones campesinas generadoras de climas de unidad familiar sin violencia, talleres de cultura jurídica, hombres miembros de familias de la Iglesia con mirada crítica hacia las inequidades y las construcciones tradicionales de género, actividades artísticas y culturales (exposiciones de pintura y fotografía, encuentros culinarios entre hombres, concursos literarios), obras audiovisuales desde la mirada de jóvenes realizadores, varones jóvenes por la equidad desde sus experiencias de vida, el deporte y la competencia sana en la vida de los hombres, juristas y policías desmontando estereotipos de género y mitos acerca de la violencia, por solo citar algunos de los más importantes.

Se pretende que cada ámbito de actuación, a partir de acciones particulares en las localidades, pueda rescatar sus experiencias más enriquecedoras, su genuinidad, visiones, fortalezas y debilidades para buscar los puntos de encuentro y las diferencias con grupos de otros territorios, y poder establecer cómo han revisado sus encargos sociales acerca de lo que significa ser hombre. De esta forma ha podido debatir experiencias que contribuyen a clarificar, mover o cambiar formas de actuación con relación a la equidad y la violencia. El resultado de estos debates grupales locales ha sido el insumo fundamental del que se ha alimentado esta agenda de trabajo.

Los debates y encuentros de la plataforma han colocado a los varones .en mejores condiciones de fomentar acciones para concientizar el trabajo por la no violencia y la equidad de género.

Algunas de las principales fortalezas del trabajo que hemos podido visualizar, monitorear y evaluar como resultado de esta experiencia han indicado fisuras en las construcciones tradicionales de lo que significa ser varón, a saber:

- la posibilidad de identificar cualquier expresión de violencia;

- el ser capaces de verbalizar elementos de una cultura jurídica encaminada a conocer qué deben hacer ante una manifestación de violencia y cuáles son los mecanismos de protección a aquellas personas que han resultado víctimas;

- acercarse a personal especializado para solicitar ayuda;

- la revisión de algunos encargos normativos de género que no favorecen el desarrollo de relaciones equitativas con las mujeres y otros hombres;

- evaluar las discriminaciones como un asunto de desigualdad y violación de derechos.

Sin embargo aún subsisten dimensiones, en los varones de esta experiencia, que es preciso atravesar y que tienen que ver con la consistencia de lo que significa ser varón según 
lo establecido por la cultura: emocionalidad reprimida, ostentación de su fortaleza física y "su grandeza", sexualidad presente, segura y resistente y el alejamiento de toda señal que suponga posiciones de autocuidado. Sin embargo aun cuando siguen figurando en su listado de asignaciones se aprecia cierto nivel de cuestionamiento en cuanto a su legitimidad. No se asume pero se reflexiona críticamente, lo que pudiera sugerir un emergente de cambio.

\section{SEÑALES PARA ORIENTARNOS}

La atención a los problemas de la violencia y las inequidades de género supone diseñar e implementar diversidad de vías para la prevención y atención de un fenómeno complejo y de amplia presencia en las concepciones y comportamientos sociales, pero también implica lograr conciencia de lo que representa, en aras de fortalecer el trabajo de gobiernos, instituciones, organizaciones y redes sociales (Cantera, 2001). Es decir, reconocer el valor de un accionar colectivo en diversas esferas de la realidad social con un trabajo de prevención y atención desde diversas perspectivas. La prevención de la violencia de género y la búsqueda de la equidad debe articularse como un proceso integrador.

El panorama contemporáneo de socialización de las masculinidades indica la urgencia de hacer apuestas sociales y culturales dirigidas a generar cambios en los hombres en relación con la violencia y la equidad de género: primero, porque son ellos los principales perpetradores de la violencia y, segundo, porque hay que desmontar los beneficios que supone sostener el poder a costa de ella.

Nuestra experiencia de trabajo con hombres ha indicado que no se pueden modificar comportamientos ni estilos de vida en relación con la violencia si los hombres no son capaces de identificarla, reconocerla, visualizarla, nombrarla, desnaturalizarla, y si no cuentan con los argumentos precisos y los recursos emocionales necesarios para ello, pero sobre todo, si no logramos que se interiorice que esta violencia descansa en inequidades históricas que generan desigualdades y desbalances de poder y que tienen su origen en la culturalización de género a la que han de responder los hombres en su camino para aprender a serlo.

Es importante que cada hombre desarrolle fortalezas que le permitan participar, revisar y analizar las formas tradicionales en que ha sido socializada su masculinidad desde los presupuestos de la cultura patriarcal a fin de comprender y desarrollar conceptos de equidad, igualdad de oportunidades, derechos y desnaturalización del poder, entre otras. Esto contribuirá a interiorizar las bondades y beneficios de un proyecto de vida que apunte a relaciones más justas y equitativas con las mujeres y entre los hombres. Es decir, se trata de promover la transformación en las relaciones intra e intergenéricas, en aras de contribuir al ejercicio pleno de la equidad.

Aun cuando sabemos que los cambios en la subjetividad individual requieren una dimensión temporal, es posible obtener resultados. Numerosas estrategias educativas y socializadoras en todo el mundo mediante programas de intervención y experiencias exitosas de buenas prácticas, dan fe de ello (Montero, Bonino, 2006 y Cantera, 2001). En tal sentido consideramos que la principal fortaleza y genuinidad de esta Plataforma de Hombres Cubanos por la no Violencia y la Equidad de Género descansa en dos particularidades:

- Su heterogeneidad (agrupar hombres con una amplia diversidad sociodemográfica, cultural y social con un propósito común: detener la violencia y trabajar por la equidad de género). 
- La posibilidad de contextualizar e ilustrar el valor de la participación de los hombres en procesos transformadores y la urgencia de asumirlos desde una planeación estratégica territorial, por medio del desarrollo de experiencias exitosas locales que puedan ser sostenidas desde las políticas locales.

La estructura de trabajo con hombres, que bajo la sombrilla de OAR está potenciando esta plataforma, nos permite valorizar y redimensionar la autenticidad de ser hombre, pero para lograr consistencia en las transformaciones precisamos tiempo, sistematicidad, perseverancia, confianza y la apropiación de una filosofía de lo que verdaderamente significa ser hombres.

La Plataforma de Hombres Cubanos por la no Violencia y la Equidad de Género es un intento más de deconstruir la invulnerabilidad masculina socialmente aprendida, de multiplicar vías para concientizar las injustas y discriminatorias desigualdades entre hombres y mujeres y entre hombres y para desaprender la violencia como una de las inequidades de género más lacerantes y violadoras de los derechos humanos.

\section{BIBLIOGRAFÍA}

Artiles, L. (2007): "Género y salud. Historia y actualidades en marco de análisis para la introducción de la perspectiva de género en los procesos de salud". La Habana: Red Latinoamericana de Género y Salud Colectiva ALAMES, Instituto Superior de Ciencias Médicas, pp. 11-13.

Arés, P. (1996): "Virilidad: ¿conocemos el costo de ser hombre?", en Sexología y Sociedad, año 2, No 4, pp. 10-14.

Asamblea General de las Naciones Unidas (1993): Declaración sobre la eliminación de la violencia contra la mujer", Resolución 48/104 artículo 1 dic. Nueva York.

Bourdieau, P. (2000): La dominación masculina, Barcelona: Anagrama.

Bonino, L. (1995): Micromachismos. La violencia invisible de la pareja. Madrid: Centro de Estudios de la Condición Masculina. s/a. pp. 3-10.

Cantera (2001): "El significado de ser hombre. Guía metodológica, para el trabajo de género con hombres. Managua: Centro de Educación y Comunicación Popular.

Cazés, D. (2005): "La perspectiva de género. Guía para diseñar, poner en marcha, dar seguimiento y evaluar proyectos de investigación y acciones públicas". México D.F.: Consejo Nacional de Población y Universidad Nacional Autónoma de México.

Díaz, M. T. (1999): "El varón cubano, antes y ahora". Tesis (máster en Sexualidad). La Habana: Centro Nacional de Educación Sexual.

-- (2009): "Renuncias y compromisos. Imágenes de hombres", en Género y Comunicación. Boletín del Servicio Noticias de la Mujer de América Latina y el Caribe, año IV, № 2.

(2010-2012): "Sistematización de una experiencia comunitaria derivada del proyecto Bienestar para masculinidades en desarrollo". Informe de investigación, La Habana: Grupo de Reflexión y Solidaridad Oscar Arnulfo Romero. 
(2012): "Hombres que se miran", en Sexología y Sociedad, año 18, № 49, pp. 14-23.

Espina, M y otros (s/a): "Estudios sobre heterogeneidad social y desigualdades en Cuba". Informe de Investigación. La Habana: Centro de Investigaciones Psicológicas y Sociológicas CIPS.

Fernández, A. (1994): La concepción metodológica de la Educación Popular. La Habana: Instituto Superior Pedagógico Enrique José Varona.

Figueroa, J. G. (2001): "Varones, reproducción y derechos: ¿podemos combinar estos términos?, en Desacatos, No 6, pp. 149-164.

------ (2008): “El Colegio de México ¿Solos consigo o contra sí mismos? Apuntes epistemológicos sobre varones y ejercicio de la violencia". Medellín: III Coloquio Internacional de Estudios sobre Varones y Masculinidades.

González, J. C. (2007): Géneros prófugos: la violencia en los medios de comunicación. Disponible en www.redmasculinidades.com

------ (2011): Macho, varón masculino. Estudios de masculinidades en Cuba. La Habana: Editorial de la Mujer, pp. 49-52.

--------- y Fernández, D. (2009): "Masculinidades y deporte. Aproximaciones desde el universo del deporte. Educar", en Curitiba, sep.-dic., pp. 123-134.

Kaufman, M. (1985): The Construction of Masculinity and the Triad of Mens Violence, Toronto: Oxford University Press.

-------- (1998):"Las 7 P de la violencia".Traducido por: Laura E. Asturias (leasturias@intelnet.net. gt), disponible en www.artnet.com.br/ marko/astulist.htm

Montero, A.; Bonino, L.; Corsi, J. y Lorente, M. (2006): “Criterios de calidad para intervenciones con hombres que ejercen violencia en la pareja", en Cuadernos para el debate. Madrid: Centro de Estudios de la Condición Masculina.

Pereira, R. (2003):"El derecho a la libre orientación sexual: un derecho sexual sin protección legal en Cuba". Tesis (máster en Sexualidad), La Habana: Centro Nacional de Educación Sexual.

Proveyer, C. (2005): "La violencia contra la mujer en las relaciones de pareja. Consideraciones para su estudio", en Proveyer Cervantes, Clotilde (comp.): Selección de lecturas de sociología y política social de género. La Habana: Editorial Félix Varela, pp. 132-172.

Fleitas, R.; González, G.; Munster, B. y César, M. (2010): "50 años después: mujeres en Cuba y cambio social. Informe de Investigación", en OXFAM Internacional, p. 28.

Ramos, A. (2003): "Varones en la periferia de la masculinidad. Un estudio en varones homosexuales y con disfunción eréctil". Tesis (máster en Sexualidad), La Habana: Centro Nacional de Educación Sexual. 